\title{
Voltammetric Comparison of the Electrochemical Oxidation of Toluene on Monolithic and Reticulated Glassy Carbon Electrodes in Aqueous Medium
}

\author{
Cornelio R. Martínez, Reynaldo L. Ortiz ${ }^{*}$ \\ Universidad de los Andes, Facultad de Ciencias, Departamento de Química, Laboratorio de \\ Electroquímica, Mérida 5101-Venezuela
}

Received 24 June 2010; accepted 7 December 2010

\begin{abstract}
The electrochemical oxidation of toluene in aqueous-acid medium was studied on monolithic and reticulated glassy carbon electrodes using cyclic voltammetry. The oxidation potential was $1.7 \mathrm{~V}$ for both electrodes. However, the normalized oxidation currents were higher on reticulated glassy carbon, showing more catalytic activity than on the monolithic glassy carbon. To normalize the obtained anodic current values, a method for the determination of the electrodes effective area was used, which consists in the underpotential deposition of a copper monolayer.
\end{abstract}

Keywords: electrochemical oxidation, toluene, aqueous-acid medium, monolithic and reticulated glassy carbon, effective area.

\section{Introduction}

The electrochemical oxidation of toluene on glassy carbon has been performed in organic medium and in aqueous-organic medium [1,2]. The effect of adding water to the organic solvent causes a cathodic shift in the oxidation peak; therefore, it favors the reaction of electro-oxidation. To counter the limitations of space-time low efficiency obtained in the electrochemical processes with two dimensional electrodes (monolithic glassy carbon (MGC)), three-dimensional electrodes have been used [3]. One of the most widely used three-dimensional electrodes is the reticulated glassy carbon (RGC), whose "honeycomb" structure of open pore allows it to have a high volume vacuum, high surface area and low flow resistance [4]. These features, along with the high electrical conductivity of

\footnotetext{
* Corresponding author. E-mail address: reynaldo@ula.ve
} 
the material allow the RGC to be an attractive electrode material for use in flow systems, where the volume of the cell, the electrode geometry and the time of experimentation are key variables to improve the efficiency of oxidation processes. Among the various electrochemical applications of this material, one of the best known is the generation of hydrogen peroxide via Fentons reagent for the treatment of industrial wastewater [5].

This paper presents the voltammetric study of the electrochemical oxidation of toluene in aqueous-acid medium on MGC and RGC electrodes. This comparison will allow evaluating the catalytic effect of both electrodes, as well as the effect of the effective area on the space-time efficiency in order to use a system in a state of flux. To test this, it is proposed a method to determine real areas, which consists of depositing a monolayer of copper at underpotential on the surface of the electrodes.

\section{Methods and materials}

\section{Reagents}

Analytical grade toluene $99.7 \%$ purity was used to the saturation concentration of $5 \mathrm{mM}$ in $0.5 \mathrm{M} \mathrm{H}_{2} \mathrm{SO}_{4}$ (95-97\% purity) as supporting electrolyte. The $\mathrm{CuSO}_{4}$ was prepared at a concentration of $2 \times 10^{-3} \mathrm{M}$ in $0.1 \mathrm{M} \mathrm{H}_{2} \mathrm{SO}_{4}$. All solutions were prepared in ultrapure water $\left(18 \mathrm{M} \Omega\right.$ ) and deoxygenated with $\mathrm{N}_{2}$ before each experiment.

\section{Cells and electrodes}

Electrochemical studies were performed in a one compartment glass cell $\left(16 \mathrm{~cm}^{3}\right.$ capacity) at room temperature $\left(22^{\circ} \mathrm{C}\right)$. A monolithic glassy carbon disk and a rectangular reticulated glassy carbon sheet were used as working electrodes, whose characteristics and properties are shown in Table 1. The reference electrode was $\mathrm{Ag} / \mathrm{AgCl}$ ( $\mathrm{KCl}$ saturated) and a platinum wire was used as counter electrode.

Table 1. Characteristics and properties of monolithic and reticulated glassy carbon used as working electrodes.

\begin{tabular}{|c|c|c|c|c|}
\hline Electrode & Dimensions & $\begin{array}{c}\text { Level of } \\
\text { porosity } \\
(\mathbf{p p i})\end{array}$ & $\begin{array}{c}\text { Composition } \\
\text { in weight } *\end{array}$ & $\begin{array}{c}\text { Atomic } \\
\text { composition * }\end{array}$ \\
\hline $\begin{array}{c}\text { Monolithic } \\
\text { GC }\end{array}$ & $\begin{array}{c}\text { Radius }=9 \mathrm{~mm} \\
\text { Geometric area }=0.636 \mathrm{~cm}^{2}\end{array}$ & 0 & $\mathrm{C}: 93.26 \%$ & $\mathrm{C}: 94.85 \%$ \\
\hline $\begin{array}{c}\text { Reticulated } \\
\text { GC }\end{array}$ & $\begin{array}{c}2.72 \times 0.74 \% \\
\text { Geometric area }=279.52 \mathrm{~cm}^{2}\end{array}$ & 500 & $\mathrm{C}: 80.43 \%$ & $\mathrm{O}: 54.17 \%$ \\
\hline
\end{tabular}

*The data of composition were determinate by X-ray dispersion spectroscopy (EDAX).

\section{Instrumentation}

The electrochemical measurements were done using a potentiostat / galvanostat coupled to a computerized system for data processing. 


\section{Voltammetric study of the electrochemical oxidation of toluene on glassy carbon electrodes}

The electrochemical oxidation voltammograms of toluene $5 \mathrm{mM}$ in $0.5 \mathrm{M} \mathrm{H}_{2} \mathrm{SO}_{4}$ were obtained at a scan rate of $10 \mathrm{mV} / \mathrm{s}$ with a potential window form 0 to 2000 $\mathrm{mV}$ vs. $\mathrm{Ag} / \mathrm{AgCl}$ in both electrodes. The $\mathrm{MGC}$ was polished with alumina 0.5 micrometers and subjected to ultrasound for $10 \mathrm{~min}$ before each run. The RGC is soaked in pure ethanol for 2 hours to remove organic contaminants, and then stoked in concentrated $\mathrm{H}_{2} \mathrm{SO}_{4}$ for 2 hours and subsequent washing with ultrapure water between each stage. Before the run, the cleaning was complete with a cyclic voltammetry between +1000 and $-1000 \mathrm{mV}$ for $10 \mathrm{~min}$; this allows removing adsorbed material and functional saturated groups. Finally, a $-900 \mathrm{mV}$ pulse for 10 minutes helps to reduce remaining traces of oxygen that are left at the electrode [6].

Determination of the effective area of glassy carbon electrodes. Deposition of a monolayer of cooper at underpotential

The underpotential deposition of copper can take place on glassy carbon surface by different mechanisms depending on the glassy carbon type [7]. Herein the deposition of copper at underpotentials was carried out in both electrodes using a solution of $\mathrm{CuSO}_{4} 2 \times 10^{-3} \mathrm{M}$ in $\mathrm{H}_{2} \mathrm{SO}_{4} 0.1 \mathrm{M}$. After purging the solution with $\mathrm{N}_{2}$ for $5 \mathrm{~min}$, the electrodes were polarized to $300 \mathrm{mV}$ for 60 seconds to avoid having copper on the electrode surface at the moment of the deposition starting, then the potential is turned to a deposition potential $(-60 \mathrm{mV})$ for 200 seconds to form the monolayer of copper, followed by a linear voltammetry of stripping from the deposition potential until it reaches $300 \mathrm{mV}$ at $5 \mathrm{mV} / \mathrm{s}$. It allows to oxidize the monolayer of copper deposited at underpotential [8]. The charge associated with the oxidation peak corrected with the charge adjusted to the background $\left(\mathrm{H}_{2} \mathrm{SO}_{4} 0.1 \mathrm{M}\right)$ allows to calculate the effective area of the MGC electrode using the charge/area relation for a monolayer copper deposited on this material, which value is approximately $2 \times 10^{-4} \mathrm{C} / \mathrm{cm}^{2}$ according to Schmidt [9]. This procedure is repeated in the RGC and the charge associated to the oxidation peak allows to obtain a relation of charges between the two electrodes $\left(Q_{R G C} / Q_{M G C}\right)$ which is equivalent to the effective area ratio $\left(A_{R G C} / A_{M G C}\right)$, thus allowing to calculate the effective area of the RGC.

\section{Results and discussions}

Voltammetric study of the electrochemical oxidation of toluene on glassy carbon electrodes

Fig. 1 shows the corresponding voltammograms of the electrochemical oxidation of toluene in both electrodes. In both cases the observed peak potential is $1.7 \mathrm{~V}$ and for the oxidation wave on MGC and RGC respectively. This value is lower than the one reported by D'Elia L.F [1] in a mixture $70 \%$ aqueous - 30\% organic with a value of oxidation potential $1.95 \mathrm{~V}$. This confirms that water causes a cathodic shift in the oxidation potential of toluene, favoring the reaction of 
electrooxidation. The absolute current of oxidation observed in the RGC is 65 times higher than in the MGC.
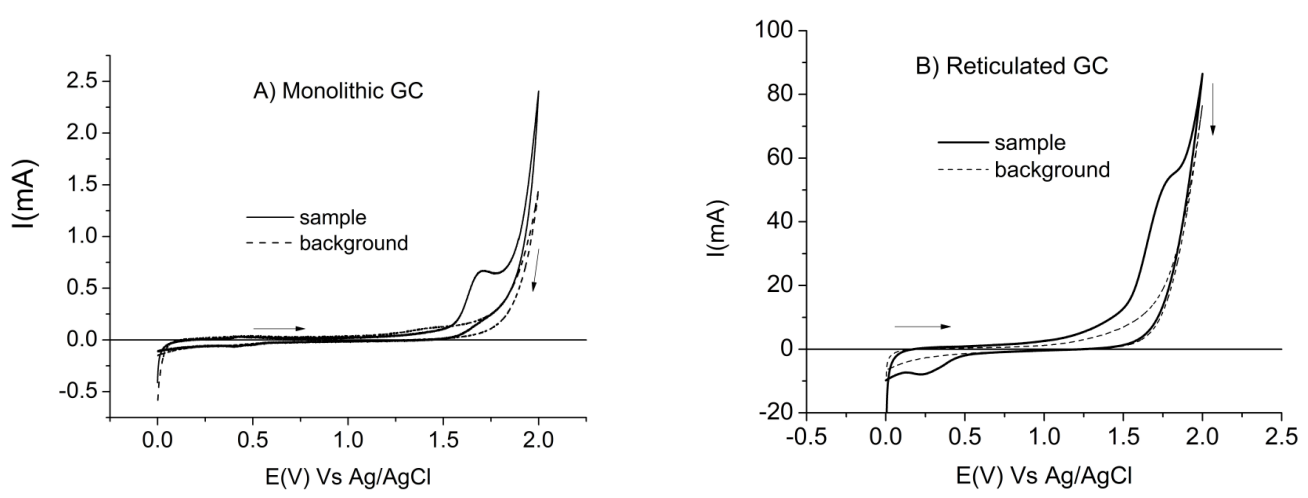

Figure 1. Voltammetric response of monolithic (A) and reticulated (B) glassy carbon electrode in toluene $5 \mathrm{mM}$ dissolved in $\mathrm{H}_{2} \mathrm{SO}_{4} 0.5 \mathrm{M}$. Scan rate $10 \mathrm{mV} / \mathrm{s}$.

If we compare the ratio of geometric areas of both electrodes (439 times), it should be expected a current ratio similar to that value, so we can infer that normalizing currents with the geometrical area would not be appropriate, besides, there are diffusional limitations of the electroactive species to the entire electrode surface and the roughness of them also plays an important role in the effective area (see micrographs in Fig. 2 A and B). Therefore, it is necessary to develop a method that allows estimating the effective area, thus proving the catalytic effect of both electrodes. However, one can conclude that the use of RGC can oxidize the most quantity of toluene for the same cell volume $\left(16 \mathrm{~cm}^{3}\right)$ and thereby improving space-time efficiency of the oxidation process, thus becoming a promising material for the oxidation of toluene in flow systems.

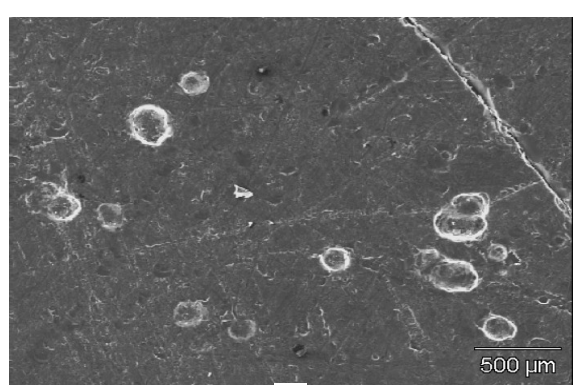

a)

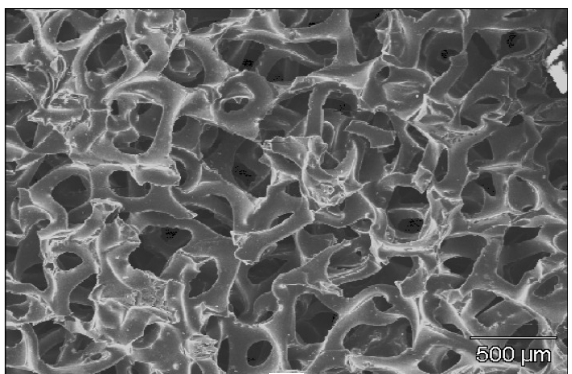

b)

Figure 2. Electronic scanning micrographs of monolithic (a) and reticulated (b) glassy carbon. $500 \mu \mathrm{m}$ approach.

Determination of the effective area of glassy carbon electrodes. Deposition of the monolayer of copper at underpotential

The voltammograms of Fig. 3 show the reduction peak of the copper deposit on the surface of both electrodes at $-80 \mathrm{mV}$; it is also noted the clear differences in the values of peak current, i.e., $-0.17 \mathrm{~mA}$ and $-13 \mathrm{~mA}$, for the monolithic and reticulated glassy carbon, respectively, due to the differences in their effective 
areas. In the backward scan it is shown the oxidation peak of the layers of stripped copper.
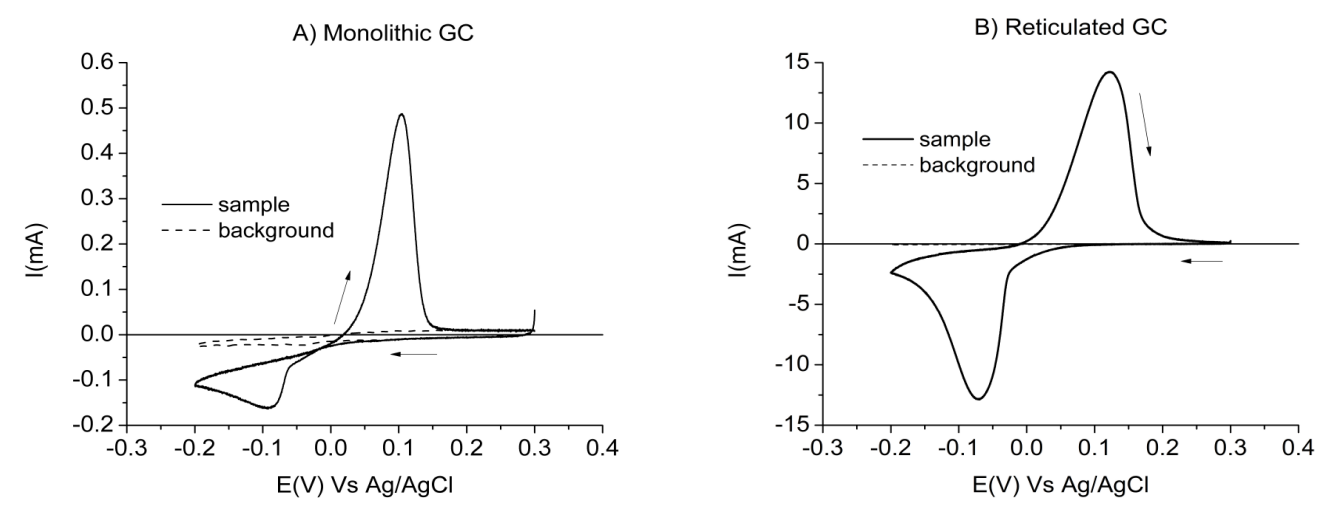

Figure 3. Voltammetric response of monolithic (A) and reticulated (B) glassy carbon electrode in $\mathrm{CuSO}_{4} 2 \times 10^{-3} \mathrm{M}$ dissolved in $\mathrm{H}_{2} \mathrm{SO}_{4} 0.1 \mathrm{M}$. Scan rate $5 \mathrm{mV} / \mathrm{s}$.

\section{Effect of the underpotential deposition on the extent of copper in the electrode surface}

Our purpose is to deposit a monolayer of copper at underpotential, so there is no possibility of three-dimensional growth of copper mass deposits. It is evidently clear that at potentials lower than $-80 \mathrm{mV}$, the massive deposition of copper takes place. Between $-70 \mathrm{mV}$ and $-60 \mathrm{mV}$ the charge does not change in the monolithic glassy carbon, and between $-80 \mathrm{mV}$ and $-40 \mathrm{mV}$ in reticulated glassy carbon, indicating that the monolayer of copper is completely formed over the entire surface of the electrode and there is no contribution of mass deposit of copper. At potentials higher than $-60 \mathrm{mV}$ (monolithic GC) and $-40 \mathrm{mV}$ (reticulated GC) the charge is less, indicating that the monolayer is not fully formed (see Fig. 4).
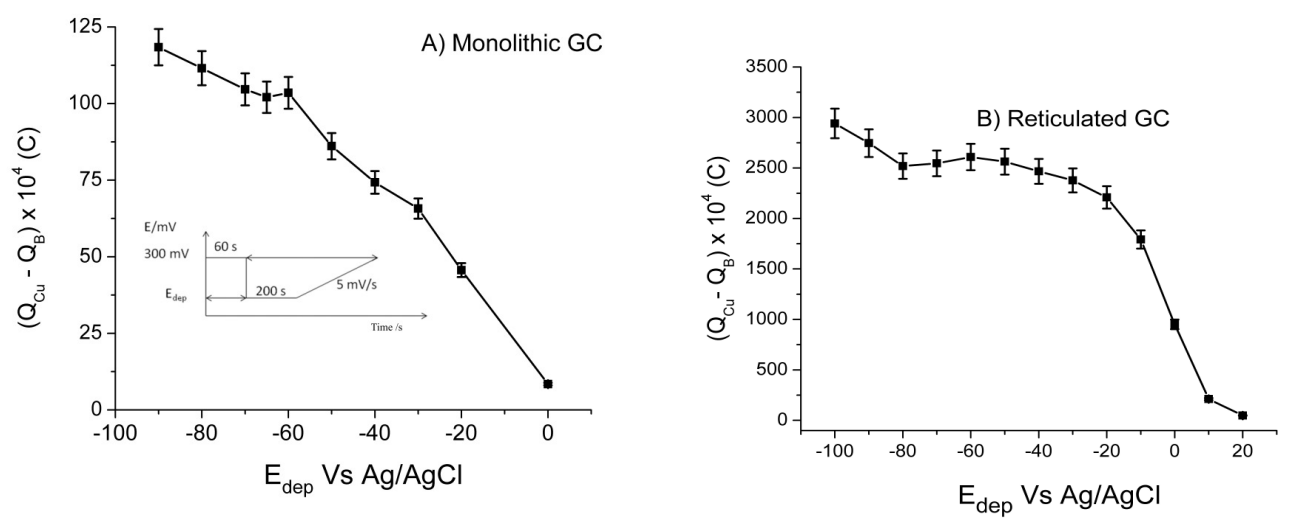

Figure 4. Total charge of oxidation of stripped copper as a function of deposition potential. A) on monolithic and $\mathrm{B}$ ) on reticulated glassy carbon in $\mathrm{CuSO}_{4} 2 \times 10^{-3} \mathrm{M}$ diluted in $\mathrm{H}_{2} \mathrm{SO}_{4} 0.1 \mathrm{M}$. Scan rate $5 \mathrm{mV} / \mathrm{s}$. The insert shows the potential pulse program and stripping applied. 


\section{Effect of deposition time on the coverage of $\mathrm{Cu}$ in the electrode surface}

The monolayer of copper is not deposited instantaneously and may require some time to be fully formed, so it is necessary to study the effect of deposition time on the total coverage of the monolayer. At short time is observed (Fig. 5) a significant increase of the charge of oxidation of copper deposited more intensely in the RGC than in the MGC, indicating the presence of more adsorption sites in the first. At long times, the charge remains constant indicating that the deposition process has been completed. In the MGC it has been reached a maximum charge of $102.08 \times 10^{-4} \mathrm{C}$ at $170 \mathrm{~s}$, and in the RGC the maximum charge reached was $2113.06 \times 10^{-4} \mathrm{C}$ at $70 \mathrm{~s}$. These charge values allow estimating the effective area of both electrodes which are shown in Table 2. With these data of effective area the oxidation currents of toluene can be normalized on both electrodes presented in the voltammograms of Fig. 1.

Table 2. Charges of oxidation of copper and real effective area of MGC and RGC electrodes.

\begin{tabular}{|c|c|c|c|}
\hline Electrode & Charge $x 1^{-4}(\mathrm{C})$ & $\begin{array}{c}\text { Relation of charges } \\
\left(\mathbf{Q}_{\mathrm{RGC}} \mathbf{Q}_{\mathrm{MGC}}\right)\end{array}$ & $\begin{array}{c}\text { Real effective area } \\
\left(\mathrm{cm}^{2}\right)\end{array}$ \\
\hline Monolithic GC & 102.08 & \multirow{2}{*}{20.7} & 51.04 \\
\hline Reticulated GC & 2113.06 & & 1056.53 \\
\hline
\end{tabular}

According to Fig. 6, the RGC electrode is more catalytic than MGC for the electrochemical oxidation of toluene in aqueous acid.
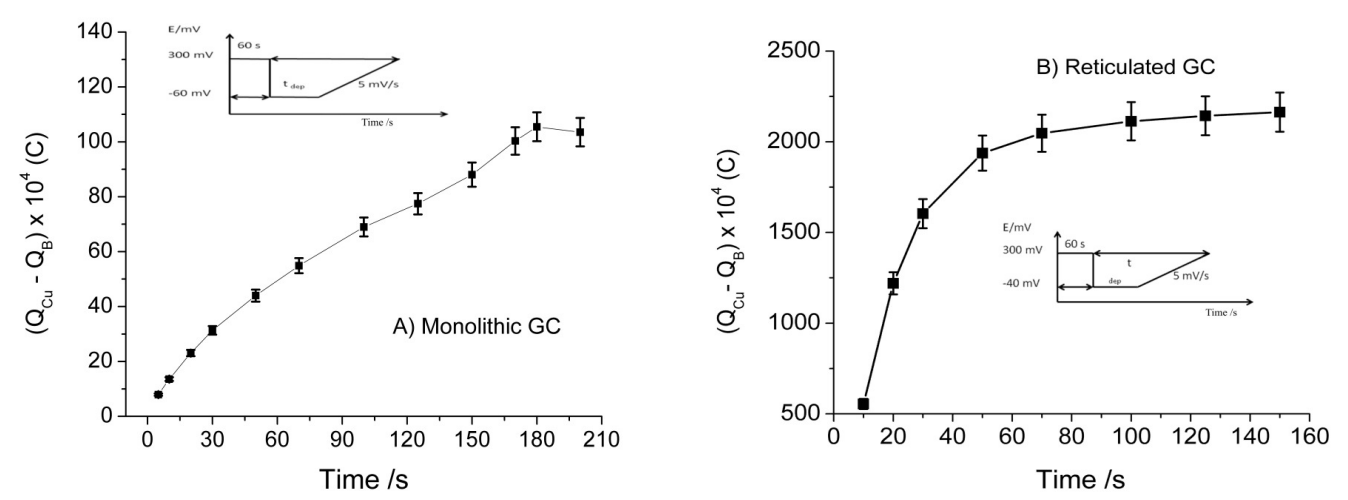

Figure 5. Total oxidation charge of stripped copper as a function of deposition time. A) on a MGC (potential of deposition $-60 \mathrm{mV}$ ) and B) on RGC (potential of deposition -40 $\mathrm{mV}$ ) in $\mathrm{CuSO}_{4} 2 \times 10^{-3} \mathrm{M}$ dissolved in $\mathrm{H}_{2} \mathrm{SO}_{4} 0.1 \mathrm{M}$. Scan rate $5 \mathrm{mV} / \mathrm{s}$. Insert shows the potential pulse and stripping programs implemented in both electrodes. 


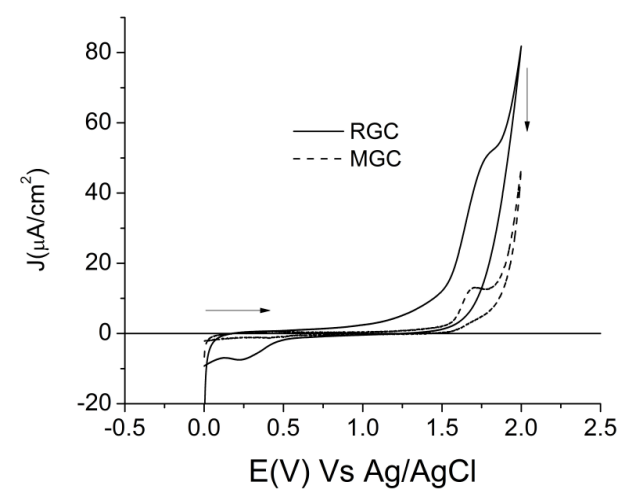

Figure 6. Voltammetric response of $\mathrm{MGC}$ and RGC electrodes in toluene $5 \mathrm{mM}$ dissolved in $\mathrm{H}_{2} \mathrm{SO}_{4} 0.5 \mathrm{M}$. Scan rate $10 \mathrm{mV} / \mathrm{s}$. The current density was estimated using the real effective area of the electrodes. The real effective areas were $51.04 \mathrm{~cm}^{2}$ for the MGC and $1056.53 \mathrm{~cm}^{2}$ for the RGC.

\section{Conclusions}

The electrochemical oxidation of toluene in aqueous acid over MGC and RGC electrodes occurs at lower potential $(1.7 \mathrm{~V})$ in aqueous-organic systems. The large surface area of the RGC allows to oxidizing greater quantities of toluene per unit of reactor volume, thereby improving the efficiency of space-time process. The proposed method for determining the effective areas suggests that the RGC is more catalytic than the MGC for toluene oxidation in this medium.

\section{Acknowledgments}

This project was supported by CDCHTA-ULA under project C-1596-08-08-B.

The authors also are grateful for support received from FONACIT (Misión Ciencia) and Departamento de Química de la Universidad Experimental Francisco de Miranda, Republica Bolivariana de Venezuela.

\section{References}

1. Luis F.D`Elia, R.Ortiz, Port. Electrochim. Acta 23 (2005) 481-490. 10.4152/pea.2005044481

2. Luis F.D`Elia, R.Ortiz, J. Electrochem. Soc. 153 (2006) D187-D192. 10.1149/1.2358120

3. A. Tentorio, U. Casolo-Ginelli, J. Appl. Electrochem. 8 (1978) 195-205. 10.1007/BF00616422

4. J.M. Friedrich, C. Ponce-de-León, G.W. Reade, F.C. Walsh J. Electroanal. Chem. 561 (2004) 203-217. 10.1016/j.jelechem.2003.07.019

5. A. Alvarez-Gallegos, D. Pletcher, Electrochimica Acta 44 (1998) 853-861. 10.1016/S0013-4686(98)00242-4

6. J. Wang, Electrochimica Acta 26 (1981) 1721-1726. 10.1016/00134686(81)85156-0

7. S. Jaya, T.P. Rao, G.P. Rao, Electrochimica Acta 31 (1986) 343-348. 10.1016/0013-4686(86)80088-3 
8. C.L. Green, A. Kucernak, J. Phys. Chem. B 106 (2002) 1036-1047. 10.1021/jp0131931

9. H. Ezaki, M. Morinaga, S. Watanabe, Electrochimica Acta 38 (1993) 557580. 10.1016/0013-4686(93)85012-N 